\title{
Cloud Point Extraction of Trace Amounts of Copper and Its Determination by Flow Injection Flame Atomic Absorption Spectrometry
}

\author{
Neda Baghban, Ali Mohammad Haji Shabani, Shayessteh Dadfarnia, ${ }^{*}$ and Abbas Ali Jafari
}

Department of Chemistry, Faculty of Science, Yazd University, Yazd, 89195-741, Iran

\begin{abstract}
A simple and convenient method based on cloud point extraction was proposed for the determination of copper. The extraction was carried out in the presence of 2-[(2-mercaptophenylimino)methyl]phenol (MPMP) as the chelating ligand and octylphenoxypolyethoxyethanol (Triton X-114) as the non-ionic surfactant. After phase separation, the surfactant rich phase containing the complex was diluted with $1.0 \mathrm{~mol} \mathrm{~L}^{-1}$ solution of $\mathrm{HNO}_{3}$ in methanol and the analyte concentration was determined by flow injection flame atomic absorption spectrometry. Under the optimum conditions, an enhancement factor of 81 was obtained for the preconcentration of copper with $25 \mathrm{~mL}$ sample solution. The calibration graph was linear in the range of $1-150 \mu \mathrm{g} \mathrm{L}^{-1}$, the relative standard deviation (RSD) for ten replicate determinations at $80 \mu \mathrm{g} \mathrm{L}^{-1} \mathrm{Cu}$ level was $1.8 \%$, and the limit of detection ( $3 \mathrm{~s}$ ) and quantification (10 s) were 0.15 and $0.50 \mu \mathrm{g} \mathrm{L}^{-1}$ respectively. The accuracy of method was confirmed by analysis of certified reference materials and recovery experiments. The proposed method was successfully applied to the determination of copper in rice flour and water samples. (doi: $10.5562 / \mathrm{cca} 1803$ )
\end{abstract}

Keywords: copper, flow injection flame atomic absorption spectrometry, cloud point extraction, Triton $\mathrm{X}-114,2-[(2-$ mercaptophenylimino)methyl] phenol

\section{INTRODUCTION}

Copper is an essential micronutrient and plays an important role in carbohydrate and lipid metabolism, but at high concentrations it is an environmental pollutant and is toxic. ${ }^{1-3}$ Therefore, the accurate and sensitive procedures for its determination at trace and ultratrace levels are important.

Flame atomic absorption spectrometry (FAAS) is one of the techniques most extensively used for the determination of metal ions. This analytical technique presents some desirable characteristics such as good selectivity, low cost, operational facilities and high analytical frequency. However, FAAS lacks the sensitivity necessary for direct determination of analyte at low levels. ${ }^{4,5}$ Thus, a preconcentration and separation step is usually needed before measuring. Various separation techniques including solid phase extraction, ${ }^{6,7}$ coprecipitation, ${ }^{8}$ solvent extraction, ${ }^{9}$ dispersive liquidliquid extraction, ${ }^{10}$ and cloud point extraction ${ }^{11-16}$ have been proposed for separation and preconcentration of copper in order to improve the inadequate sensitivity of FAAS and reduce the matrix effect. Among these meth- ods, recently, cloud point extraction has attracted considerable attention mainly because it is in consistence with the "green chemistry" principles. ${ }^{17}$ Some advantages of $\mathrm{CPE}$ extraction are low cost, safety, simplicity, fast operation, no need for large amounts of toxic organic solvent, high preconcentration factor, and ease of coupling to analytical instruments. ${ }^{18-20}$ This method is based on the property that an aqueous solution of surfactants forms micelles and becomes turbid above a temperature defined as cloud point temperature. Above the cloud point temperature, the original surfactant solution separates into a small volume of surfactant rich phase and a bulk of diluted aqueous phase, in which the concentration of surfactant is close to the critical micellar concentration (CMC). Any analyte solubilized in the hydrophobic core of the micelles will be concentrated into the small volume of the surfactant rich phase which can subsequently be determined by different spectrometric techniques such as flame atomic absorption spectrometry (FAAS), ${ }^{21}$ electrothermal atomic absorption spectrometry (ETAAS), ${ }^{22}$ inductively coupled plasma mass spectrometry (ICP-MS) ${ }^{23}$ inductively coupled plasma optical emission spectrometry (ICP-

\footnotetext{
* Author to whom correspondence should be addressed. (E-mail: sdadfarnia@yazduni.ac.ir)
} 
OES), ${ }^{24}$ laser induced-thermal lens spectrometry (LITLS), ${ }^{25}$ and spectrophotometry. ${ }^{26}$

2-[(2-mercaptophenylimino)methyl]phenol (MPMP) (Figure 1) is a Schiff base and forms stable complexes with some transition metal ions. MPMP has been used as a hydrophobic chelating agent for analytical purposes due to its high stability and its low solubility in aqueous solution. ${ }^{27-29}$ In this work a novel and convenient cloud point extraction method for the separation and preconcentration of trace copper in aqueous samples prior to its determination by FI-FAAS is described. The method is based on the formation of $\mathrm{Cu}$ (II) complex with 2-[(2-mercaptophenylimino)methyl]phenol (MPMP) (Figure 1) followed by its extraction into surfactant-rich phase Triton X-114.

\section{EXPERIMENTAL}

\section{Apparatus}

A Buck Scientific atomic absorption spectrometer (model 210 VCP, East Norwalk, CT, USA), equipped with a copper hollow cathode lamp (current, $i=3.2 \mathrm{~mA}$ and slit width, $s=0.7 \mathrm{~nm}$ ) was used for the determination of copper at wavelength $\lambda=324.7 \mathrm{~nm}$. A single line flow injection system as described before ${ }^{30}$ i.e. is consisted of a peristaltic pump (Ismatic, MS-REGLO/8100 , Zurich, Switzerland) and a rotary injection valve (Rheodyne, Rohnert Park, CA, USA) was used for effective control of the amount of sample and repeatability of the measurements. The $\mathrm{pH}$ of solutions was controlled with a Metrohm pH meter (model 691, Herisau, Switzerland) using a combined glass calomel electrode. A thermostatic bath (Shimi Fann, model S.57, Tehran, Iran) and a centrifuge (Hittich, Universal 320, Tuttingen, Germany) were used to accelerate the phase separation process.

\section{Reagents}

All chemicals were of analytical grade reagents. Doubly distilled, deionized water was used throughout. The stock solution of copper $\left(1000 \mathrm{mg} \mathrm{L}^{-1}\right)$ was prepared by dissolving an appropriate amount of $\mathrm{Cu}\left(\mathrm{NO}_{3}\right)_{2} \cdot 3 \mathrm{H}_{2} \mathrm{O}$ (E. Merck, Darmstadt, Germany) in water and diluting to the mark in a $100 \mathrm{~mL}$ volumetric flask. Working standard solutions were prepared daily from the stock solution by appropriate dilution with water. Triton X114 (volume concentration, $\varphi=2.5 \%$ ) stock solution was prepared by dissolving $2.5 \mathrm{~mL}$ of the concentrated solution (Fluka, Chemie AG, Buches, Switzerland) in hot distilled water and diluting to $100 \mathrm{~mL}$. A $0.1 \mathrm{~mol} \mathrm{~L}^{-1}$ stock buffer solution ( $\mathrm{pH}=4.5$ ) was prepared by using sodium acetate and hydrochloric acid (E. Merck, Darmstadt, Germany) at appropriate concentrations. 2-[(2mercaptophenylimino)methyl]phenol was synthesized

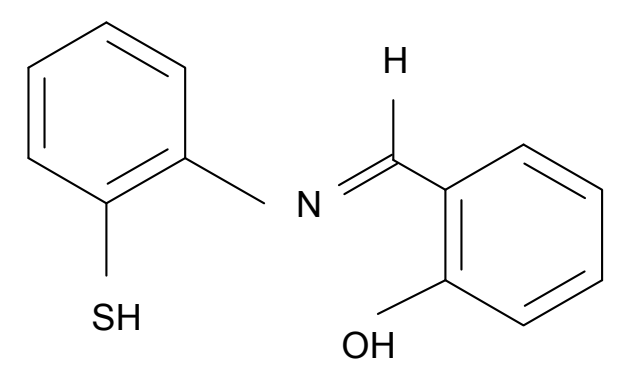

Figure 1. Chemical structure of MPMP.

and purified according to the literature. ${ }^{31,32}$ The solution of $1 \times 10^{-2} \mathrm{~mol} \mathrm{~L}^{-1}$ MPMP was prepared by dissolving a proper amount of the reagent in ethanol.

\section{General Procedure}

An aliquot of $25 \mathrm{~mL}$ of a solution containing $\mathrm{Cu}$ (II) $\left(1-150 \mu \mathrm{g} \mathrm{L}^{-1}\right), 0.8 \mathrm{~mL}$ of solution of Triton X-114 (volume concentration, $\varphi=2.5 \%$ ), $0.25 \mathrm{~mL}$ of $1 \times 10^{-2}$ mol L ${ }^{-1}$ of MPMP, and $2 \mathrm{~mL}$ of acetate buffer $(\mathrm{pH}=4.5)$ was kept for $5 \mathrm{~min}$ in the thermostatic bath at $55^{\circ} \mathrm{C}$. Separation of the phases was achieved by centrifugation for $10 \mathrm{~min}$ at $3500 \mathrm{rpm}$. The mixture was cooled in an ice bath for $5 \mathrm{~min}$ which increased the viscosity of the surfactant-rich phase and the aqueous phase was easily decanted by inverting the tube. In order to decrease the viscosity and facilitate sample handling, the surfactant rich phase was diluted to $300 \mu \mathrm{L}$ with $1.0 \mathrm{~mol} \mathrm{~L}^{-1}$ solution of $\mathrm{HNO}_{3}$ in methanol. Finally, $100 \mu \mathrm{L}$ of the resulting solution was introduced into the FAAS by a single line flow injection system at a flow rate of $2.5 \mathrm{~mL} \mathrm{~min}^{-1}$ (Figure 2).

\section{Water Preparation}

To remove suspended particulate matter, water samples were filtered through a $0.45 \mu \mathrm{m}$ pore size membrane filter into cleaned polyethylene bottles and were stored in $5{ }^{\circ} \mathrm{C}$ before analysis. $25 \mathrm{~mL}$ of it was treated according to the given procedure.

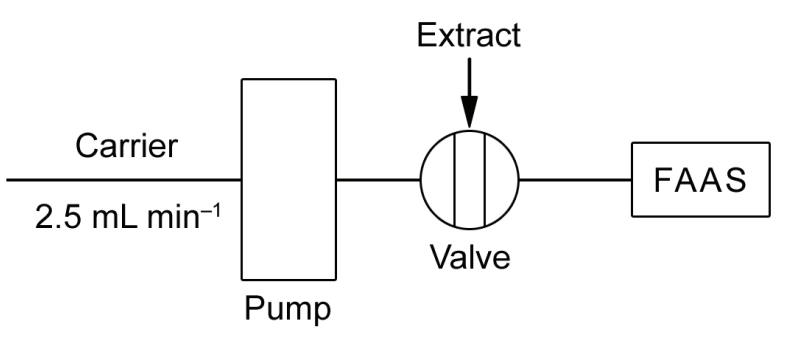

Figure 2. Flow injection system coupled to flame atomic absorption spectrometry for the injection and determination of copper. 


\section{Rice Flour Preparation}

One gram of rice flour was placed in a $100 \mathrm{~mL}$ beaker, $7 \mathrm{~mL}$ concentrated nitric acid and $4 \mathrm{~mL}$ of hydrogen peroxide $(\rho=30 \%)$ was added and the mixture was heated on a hot plate for $10 \mathrm{~min}$. Then the solution was cooled to room temperature, filtered and after adjustment of $\mathrm{pH}$ to $\sim 4.5$, the mixture was diluted to the final volume of $100 \mathrm{~mL}$ with distilled water and was treated according to the given procedure. The recovery experiments was done by spiking $1 \mathrm{~g}$ of rice flour with 2 and 5 $\mu \mathrm{g}$ of copper ions, digested and diluted as described above and was analyzed according to the given procedure.

\section{Preparation of Certified Lead Sample}

Five milliliter of concentrated nitric acid was added to $0.25 \mathrm{~g}$ of a certified lead sample (BCR No. 288). The solution was heated over a water bath for few minutes and $3 \mathrm{~mL}$ of hydrogen peroxide $(\rho=30 \%)$ was added. The solution was filtered, diluted with distilled water and the $\mathrm{pH}$ was adjusted to $\sim 4.5$ with $0.1 \mathrm{~mol} \mathrm{~L}^{-1}$ ammonia solution. The solution was then transferred into a $100 \mathrm{~mL}$ volumetric flask and diluted to the mark with distilled water. $25 \mathrm{~mL}$ of it was treated according to the given procedure.

\section{RESULTS AND DISCUSSION}

Separation of metal ions by CPE often involves the formation of a hydrophobic complex to be extracted into the surfactant-rich phase. Preliminary experiments confirmed that MPMP forms a stable complex with copper ions, which is extractable into surfactant-rich phase of Triton X-114. MPMP has one oxygen, one sulfur and one nitrogen donating group in its structure and acts as three dentated ligand. The ligand forms a stable 1:1 complex with copper(II). ${ }^{32}$ In order to establish the best conditions for the formation and extraction of complex, the effective parameters such as $\mathrm{pH}$, concentrations of ligand and surfactant, temperature, and incubation time were optimized by univariable method.

The $\mathrm{pH}$ of sample solution is one of the influencing factors in the cloud point extraction of metal ions, since the extraction yield depends on the $\mathrm{pH}$ at which complex formation occurs. The influence of $\mathrm{pH}$ on the extraction of $\mathrm{Cu}^{2+}$ was evaluated in the $\mathrm{pH}$ range of 1-11. Figure 3 shows that the absorbance is nearly constant in the $\mathrm{pH}$ range of $4-8$. The possibility of extraction in a wide $\mathrm{pH}$ range can be mentioned as an advantage of this method. The decrease in absorbance at $\mathrm{pH}$ greater than 8 is probably due to the precipitation of copper as copper hydroxide, whereas the signal decrease at $\mathrm{pH}<4$ may be due to the competition between hydronium and analyte for reaction with MPMP. Hence, a $\mathrm{pH}$ of 4.5 was chosen for further extractions.

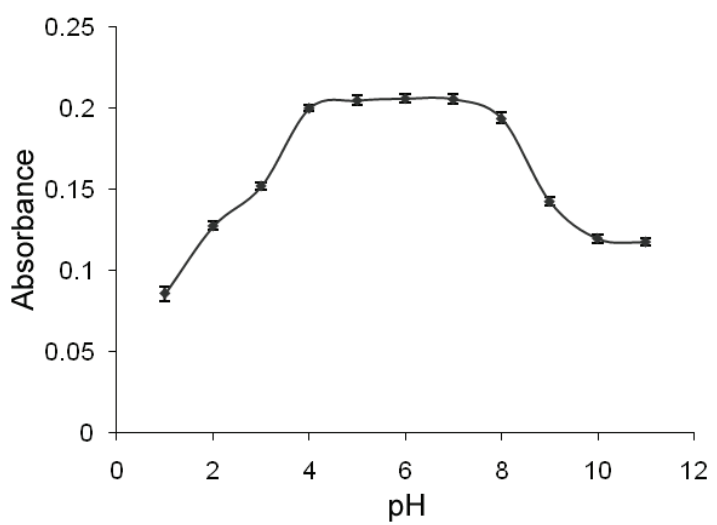

Figure 3. Effect of $\mathrm{pH}$ on the cloud point extraction of copper. Conditions: $\rho(\mathrm{Cu})=80 \mu \mathrm{g} \mathrm{L}^{-1}, c(\mathrm{MPMP})=1.2 \times 10^{-4} \mathrm{~mol} \mathrm{~L}^{-1}$, and $\varphi($ Triton $\mathrm{X}-114)=0.1 \%$.

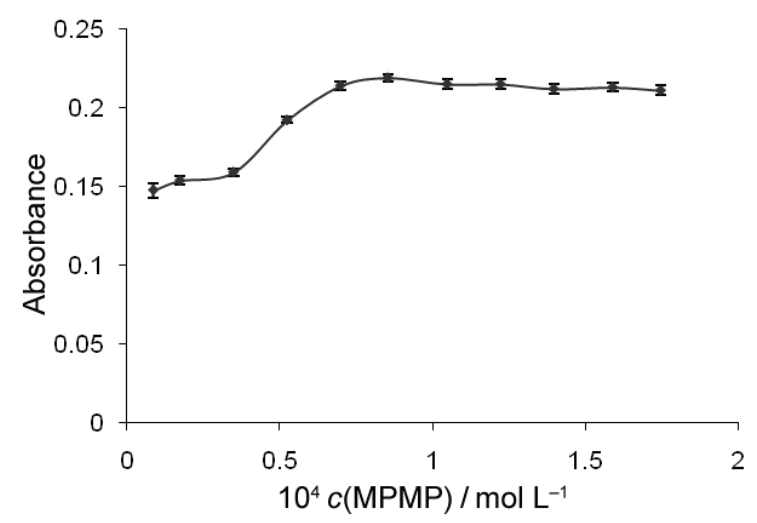

Figure 4. Effect of MPMP concentration on the cloud point extraction of copper. Conditions: $\rho(\mathrm{Cu})=80 \mu \mathrm{g} \mathrm{L}^{-1}, \varphi$ (Triton $\mathrm{X}-114)=0.1 \%$, and $\mathrm{pH}=4.5$.

The variation of absorbance as a function of the MPMP concentration was investigated for copper complex formation during the cloud point extraction procedure. Concentration of MPMP was varied in the range of $0.1-1.7 \times 10^{-4} \mathrm{~mol} \mathrm{~L}^{-1}$. Figure 4 shows the absorbance increases by increasing ligand concentration up to a concentration of $9 \times 10^{-5} \mathrm{~mol} \mathrm{~L}^{-1}$ of ligand and thereafter reaches a plateau. Thus, a concentration of $1 \times 10^{-4}$ mol L ${ }^{-1}$ of MPMP was chosen for further experiments.

Triton X-114 was selected for cloud point extraction of copper complex because of its commercial availability, low cloud point temperature and high density ${ }^{33,34}$ Another factor which has unique role in CPE is surfactant concentration as it determines the narrow range in which maximum extraction efficiency and analytical signal are achieved. The effect of Triton X114 volume concentration, $\varphi$ on copper extraction was investigated in the range of $0.01-0.15 \%$. As can be seen from Figure 5, the absorbance increased by increasing Triton X-114 volume concentration, $\varphi$ up to $0.08 \%$ and then leveled off at higher concentration. The 


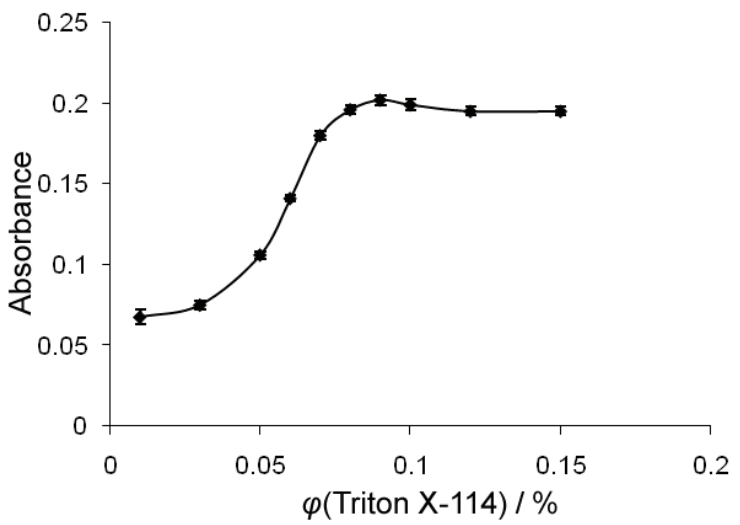

Figure 5. Effect of Triton $\mathrm{X}-114$ concentration on the cloud

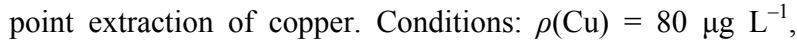
$c(\mathrm{MPMP})=1 \times 10^{-4} \mathrm{~mol} \mathrm{~L}^{-1}$, and $\mathrm{pH} 4.5$.

progressive decrease in the absorbance at lower concentrations of Triton $\mathrm{X}-114$ is due to inadequacy of the surfactant assemblies to entrap the hydrophobic complex quantitatively. Triton X-114 volume concentration, $\varphi$ of $0.08 \%$ was chosen as the optimum concentration.

Equilibrium temperature and the incubation time were also optimized. The effect of equilibrium temperature was investigated in the range of $t=25-85^{\circ} \mathrm{C}$. As Figure 6 shows the absorbance of the analyte reach

Table 1. Tolerance limits of interfering ions in the determination of $\mathrm{Cu}, \rho(\mathrm{Cu})=20 \mu \mathrm{g} \mathrm{L}^{-1}$

\begin{tabular}{lc}
\hline \multicolumn{1}{c}{ Ion } & $\begin{array}{c}\text { Mole ratio } \\
n(\text { ion }) / n\left(\mathrm{Cu}^{2+}\right)\end{array}$ \\
\hline $\mathrm{K}^{+}, \mathrm{Na}^{+}, \mathrm{Mg}^{2+}, \mathrm{Ca}^{2+}, \mathrm{Sr}^{2+}, \mathrm{Zn}^{2+}, \mathrm{Mn}^{2+}$, & $1000^{(\mathrm{a})}$ \\
$\mathrm{NO}_{3}{ }^{-}, \mathrm{PO}_{4}^{3-}, \mathrm{SO}_{4}{ }^{2-}, \mathrm{CO}_{3}{ }^{2-}$ & \\
$\mathrm{Ni}^{2+}, \mathrm{Pb}^{2+}$ & 800 \\
$\mathrm{Cd}^{2+}, \mathrm{Co}^{2+}$ & 500 \\
$\mathrm{Hg}^{2+}, \mathrm{Cr}^{3+}$ & 400 \\
$\mathrm{Fe}^{2+}$ & 250 \\
$\mathrm{Ag}^{+}, \mathrm{Fe}^{3+}$ & 100 \\
\hline
\end{tabular}

${ }^{\text {(a) }}$ Maximum value tested.

Table 2. Figures of merit for $\mathrm{Cu}$ measurements by CPE-FIFAAS

\begin{tabular}{lc}
\hline \multicolumn{1}{c}{ Parameters } & Analytical feature of $\mathrm{Cu}$ \\
\hline Regression equation $^{(\mathrm{a})}$ & $A=2.532 \times 10^{-3} \mathrm{C}+0.0099$ \\
Correlation coefficient, $r$ & 0.9997 \\
Linear range in $\mu \mathrm{g} \mathrm{L}^{-1}$ & $1-150$ \\
LOD $\left(3 S_{\mathrm{b}} / m\right)$ & 0.15 \\
Enhancement factor & 81 \\
RSD in $\%(n=10)$ & 1.8 \\
\hline
\end{tabular}

(a) $C$ expressed in $\mu \mathrm{g} \mathrm{L}^{-1}$

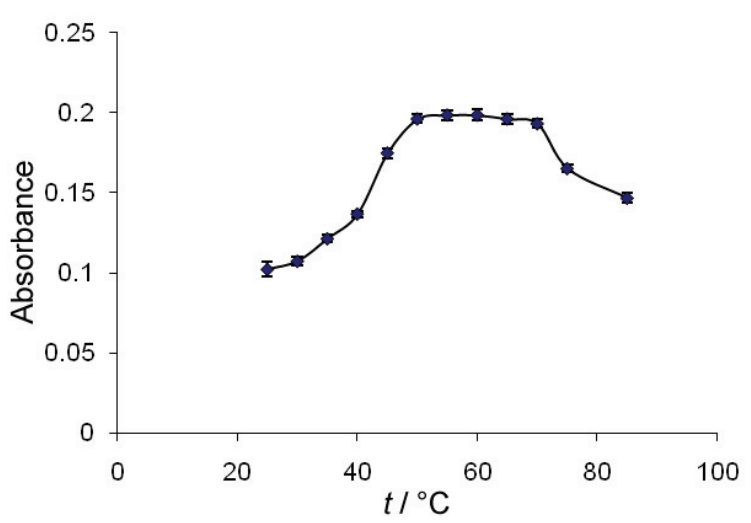

Figure 6. Effect of tempereture on the cloud point extraction of copper. Conditions: $\rho(\mathrm{Cu})=80 \mu \mathrm{g} \mathrm{L}{ }^{-1}, c(\mathrm{MPMP})=1 \times 10^{-4}$ mol L ${ }^{-1}$, and $\varphi($ Triton $\mathrm{X}-114)=0.08 \%$., and $\mathrm{pH} 4.5$.

maximum in $50-70{ }^{\circ} \mathrm{C}$. The decrease in absorbance at temperature higher than $70{ }^{\circ} \mathrm{C}$ is probably due to the decomposition of the complex which reduces the extraction efficiency. So, an equilibrium temperature of $55^{\circ} \mathrm{C}$ was selected as optimum temperature for further studies. The dependence of analytical signal upon incubation time was also investigated in the range of $1-10 \mathrm{~min}$. It was observed that an incubation time of $5 \mathrm{~min}$ is adequate for quantitative extraction.

The influence of ionic strength on the analytical signal of copper $\left(80 \mu \mathrm{g} \mathrm{L}^{-1}\right)$ was studied.The results showed that addition of $\mathrm{NaCl}$ in the interval of $0.1-0.7$ mol $\mathrm{L}^{-1}$ has no significant effect on the sensitivity and cloud point extraction efficiency.

Table 3. Determination of copper in rice flour and water samples

\begin{tabular}{cccc}
\hline Samples & $\begin{array}{c}\text { Added } \\
\rho / \mu \mathrm{g} \mathrm{L}^{-1}\end{array}$ & $\begin{array}{c}\text { Found }^{(\mathrm{a})} \\
\rho / \mu \mathrm{g} \mathrm{L}^{-1}\end{array}$ & Recovery $/ \%$ \\
\hline Sea water & 0 & $6.07 \pm 0.11$ & - \\
& 10 & $15.80 \pm 0.21$ & 97.3 \\
River water 1 & 0 & $25.71 \pm 0.18$ & 98.2 \\
& 10 & $13.56 \pm 0.19$ & 95.8 \\
River water 2 & 20 & $23.76 \pm 0.09$ & 98.9 \\
& 0 & $5.01 \pm 0.07$ & - \\
Sea water & 10 & $15.00 \pm 0.07$ & 99.9 \\
& 20 & $24.77 \pm 0.19$ & 98.8 \\
& 0 & $9.83 \pm 0.03$ & - \\
Rice flour & 10 & $19.46 \pm 0.21$ & 96.3 \\
& 20 & $29.69 \pm 0.18$ & 99.3 \\
& 0 & $2.01 \pm 0.04$ & - \\
& 2 & $4.00 \pm 0.07$ & 99.5 \\
& 5 & $6.79 \pm 0.11$ & 95.6 \\
\hline
\end{tabular}

(a) Mean and standard deviation related to three determinations. 
Table 4. Comparison of analytical characteristics of the present method and some of those reported previously for the $\mathrm{CPE}$ of $\mathrm{Cu}$ and its determination by FAAS

\begin{tabular}{|c|c|c|c|c|c|c|}
\hline Reagent $^{(a)}$ & Surfactant & Sample volume $/ \mathrm{mL}$ & Dynamic range $/ \mu \mathrm{g} \mathrm{L}^{-1}$ & $\mathrm{EF}^{(\mathrm{b})}$ & $\mathrm{LOD}^{(\mathrm{c})} / \mu \mathrm{g} \mathrm{L}^{-1}$ & References \\
\hline MPKO & Triton X-114 & 15 & $10-250$ & 65 & 1.6 & 11 \\
\hline DDTC & Triton X-114 & 10 & $5-300$ & 22 & 0.5 & 12 \\
\hline PDBDM & Triton X-114 & 15 & $10-260$ & 41.1 & 0.6 & 13 \\
\hline Schiff base L & Triton X-114 & 10 & $0.1-1300$ & 20 & 0.06 & 14 \\
\hline PAN & Triton X-114 & 50 & $0.34-220$ & 34 & 0.1 & 15 \\
\hline TAN & Triton X-114 & 50 & $0.27-100$ & 64.3 & 0.27 & 16 \\
\hline 1-PTSC & Triton X-114 & 50 & $250-5000$ & 25 & 0.67 & 35 \\
\hline DDTP & Triton X-100 & 10 & $5-200$ & 33.3 & 0.94 & 36 \\
\hline Pyrogallol & Triton X-114 & 60 & $0.05-50$ & 85 & 0.05 & 37 \\
\hline $\mathrm{H}_{2}$ mdo & Triton X-114 & 20 & $0.4-150$ & 65 & 0.14 & 38 \\
\hline $\mathrm{Me}-\mathrm{BTABr}$ & Triton X-114 & 10 & $1.08-100$ & 17 & 1.08 & 39 \\
\hline Me-BDBD & Triton X-114 & 10 & $1.5-100$ & 14 & 1.5 & 40 \\
\hline NDDT & Triton X-114 & 10 & $0.22-100$ & 22.4 & 0.22 & 41 \\
\hline BDAP & Triton X-114 & 10 & $1-100$ & 29 & 0.4 & 42 \\
\hline ARS & Triton X-114 & 12 & $5-200$ & 21 & 1.07 & 43 \\
\hline IYPMI & Triton X-114 & 15 & $10-200$ & 48 & 1.6 & 44 \\
\hline PHBI & Triton X-114 & 15 & $20-260$ & 58 & 1.8 & 45 \\
\hline MPMP & Triton X-114 & 25 & $1-150$ & 81 & 0.15 & This work \\
\hline
\end{tabular}

${ }^{(a)}$ MPKO: methyl-2-pyridylketone oxime; DDTC: diethyldithiocarbamate; PDBDM: 4-(phenyl diazenyl) benzene-1,3-diamine; Schiff base L: $N, N^{\prime}$-bis(2-hydroxyacetophenone)-1,2-propanediimine; PAN: 1-(2-pyridylazo)-2-naphthol; TAN: 1-(2thiazolylazo)-2-naphthol; 1-PTSC: 1-phenylthiosemicarbazide; DDTP: $O, O$-diethyldithiophosphate; $\mathrm{H}_{2} \mathrm{mdo}: 3-[(8-\{[(\mathrm{E})-2-$ hydroxyimino-1-methylpropylidene] amino\}-1-naphthyl)imino]-2-butanone oxime; Me-BTABr: 2-[2'-(6-methyl-benzothiazolylazo)]-4-bromophenol; Me-BDBD: 6-[2'-(6'-methyl-benzothiazolylazo)]-1,2-dihydroxy-3,5-benzenedisulfonic acid; NDDT: 6-(2-naphthyl)-2,3-dihyro-as-triazine-3-thione; BDAP: 2-(2'-benzothiazolylazo)-5-( $N, N$-diethyl)aminophenol; ARS: Alizarin Red S; IYPMI: 3-((indolin-3-yl)(phenyl)methyl)indoline; PHBI: 2-phenyl-1H-benzo[d]imidazole; MPMP: 2-[(2-mercaptophenylimino)methyl]phenol.

(b) EF: Enhancement factor.

(c) LOD: limit of detection.

Furthermore, the effect of centrifugation time on the extraction efficiency was investigated in the range of 1-20 min at $3500 \mathrm{rpm}$. It was found that a centrifugation time of $10 \mathrm{~min}$ was enough for complete phase separation.

\section{Interferences}

The effect of selected cations and anions on the extraction and determination of $20 \mu \mathrm{g} \mathrm{L}{ }^{-1}$ copper by the proposed method was investigated.A relative error of less than $\pm 5 \%$ was considered to be within the range of experimental error. The results are shown in Table 1. It can be seen that the presence of other cations and anions at the given mole ratio has no significant influence on $\mathrm{CPE}$ of $\mathrm{Cu}$ under the optimum conditions.

\section{Analytical Figures of Merit}

Calibration graph for the sample volume of $25 \mathrm{~mL}$ gave good linearity over the concentration range of $1-150 \mu \mathrm{g}$ $\mathrm{L}^{-1}$ for $\mathrm{Cu}$. Table 2 summarizes the analytical character- istic of the proposed method. The relative standard deviation (RSD) for 10 replicates measurements of 80 $\mu \mathrm{g} \mathrm{L}{ }^{-1}$ of copper was $\pm 1.8 \%$. The limit of detection and quantification defined as the concentration equivalent to three times and ten times of the standard deviation of the blank divided by the slope of the calibration graph were $0.15 \mu \mathrm{g} \mathrm{L}^{-1}$ and $0.50 \mu \mathrm{g} \mathrm{L}^{-1}$, respectively. The enhancement factor calculated as the ratio of the slopes of the calibration graphs with $\left(2.532 \times 10^{-3}\right)$ and without $\left(3.126 \times 10^{-5}\right)$ preconcentration, was 81 .

\section{Application}

The proposed method has been applied to the determination of $\mathrm{Cu}$ in water samples and rice flour. The reliability of method was checked by recovery experiments. As can be seen from Table 3, in all samples, the copper recovery is almost quantitative (95.6-99.9\%), which demonstrates the applicability of the proposed method for the sample type examined.

Furthermore, in order to validate the accuracy of the method, the procedure was applied to the determination 
of copper in certified lead sample (BCR No. 288) (composition: $\mathrm{Ag}=30.5 \pm 0.5 \mu \mathrm{g} \mathrm{g}^{-1}, \mathrm{As}=55.7 \pm 1.6 \mu \mathrm{g} \mathrm{g}^{-1}$, $\mathrm{Bi}=215.8 \pm 2.4 \mu \mathrm{g} \mathrm{g}^{-1}, \mathrm{Cd}=33.3 \pm 0.9 \mu \mathrm{g} \mathrm{g}^{-1}, \mathrm{Cu}=$ $19.3 \pm 0.4 \mu \mathrm{g} \mathrm{g}^{-1}, \mathrm{Ni}=4.57 \pm 0.11 \mu \mathrm{g} \mathrm{g}^{-1}, \mathrm{Sb}=32.5 \pm$ $0.9 \mu \mathrm{g} \mathrm{g}^{-1}, \mathrm{Se}<0.2 \mu \mathrm{g} \mathrm{g}^{-1}, \mathrm{Sn}=30.6 \pm 1.5 \mu \mathrm{g} \mathrm{g}^{-1}, \mathrm{Te}=$ $32.8 \pm 1.3 \mu \mathrm{g} \mathrm{g}^{-1}, \mathrm{Tl}=2.3 \pm 0.1 \mu \mathrm{g} \mathrm{g}^{-1}$, and $\mathrm{Zn}=8.2 \pm$ $0.4 \mu \mathrm{g} \mathrm{g}^{-1}$ ) and certified rice flour (NIST-SRM 1568a). The measured amount of copper in lead sample and rice flour were found to be $18.9 \pm 0.1 \mu \mathrm{g} \mathrm{g}^{-1}$ and $2.3 \pm 0.1 \mu \mathrm{g}$ $\mathrm{g}^{-1}$, respectively, which are in good agreement with the certified values ( the accepted values are: $19.3 \pm 0.4 \mu \mathrm{g} \mathrm{g}^{-1}$ for lead sample and $2.4 \pm 0.3 \mu \mathrm{g} \mathrm{g}^{-1}$ for rice flour).

\section{CONCLUSION}

The results of this work demonstrate the possibility of using MPMP as an effective chelating agent for the cloud point extraction and separation of copper prior to its determination by FI-FAAS. The method can be successfully applied to the determination of copper in rice flour and water samples. The method proved to be convenient, rapid, and sensitive for determination of copper in real samples with limited interferences. Furthermore, the proposed method was compared with other reported methods using CPE and FAAS (Table 4). As it is demonstrated, the proposed method presents superior or comparable analytical figures of merit to reported methods.

\section{REFERENCES}

1. E. Kendüzler and A. R. Türker, Anal. Chim. Acta 480 (2003) 259-266.

2. A. B. Tabrizi, J. Hazard. Mater. B 139 (2007) 260-264.

3. P. D. Ding, L. M. Niu, H.Q. Luo, and N. B. Li, Croat. Chem. Acta 80 (2007) 61-66.

4. M. de Godoi Pereira and M. A. Z. Arruda, Microchim. Acta 141 (2003) 115-131.

5. S. Dadfarnia, M. Talebi, A. M. Haji Shabani, and Z. Amani Beni, Croat. Chem. Acta 80 (2007) 17-23.

6. S. Dadfarnia, A. M. salmanzadeh, and A. M. Haji Shabani, J. Anal. At. Spectrom. 17 (2002) 1434-1438.

7. M. Soylak and O Ercan, J. Hazard. Mater. 168 (2009) 1527 1531 .

8. G. Doner and A. Ege, Anal. Chim. Acta 547 (2005) 14-17.

9. M. Alkan and D. Kara, Instrum. Sci. Technol. 32 (2004) 291301.

10. S. Z. Mohammadi, D. Afzali, and Y. M. Baghelani, Anal. Chim. Acta 653 (2009) 173-177.

11. M. Ghaedi, A. Shokrollahi, F. Ahmadi, H. R. Rajabi, and M. Soylak, J. Hazard. Mater. 150 (2008) 533-540.

12. Y. Gao, P. Wu,W. Li, Y. Xuan, and X. Hou, Talanta 81 (2010) 586-590.

13. A. Shokrollahi, M. Ghaedi, O. Hossaini, N. Khanjari, and M. Soylak, J. Hazard. Mater. 160 (2008) 435-440.
14. S. A. M. Fathi and M. R. Yaftian, J. Colloid Interface Sci. 334 (2009) 167-170.

15. H. S. Ferreira, A. C. N. Santos, L. A. Portugal, A. C. S. Costa, M. Miró, and S. L. C. Ferreira, Talanta 77 (2008) 73-76.

16. J. Chen and K. C. Teo, Anal. Chim. Acta 450 (2001) 215-222.

17. M. A. Bezerra, M. A. Z. Arruda, and S. L. C. Ferreira, Appl. Spectrosc. Rev. 40 (2005) 269-299.

18. E. K. Paleologos, D. L. Giokas, and M. I. Karayannis, Trends Anal. Chem. 24 (2005) 426-436.

19. C. B. Ojeda and F. S. Rojas, Anal. Bioanal. Chem. 394 (2009) 759-782.

20. M. F. Silva, E.S. Cerutti, and L. D. Martinez, Microchim. Acta 155 (2006) 349-364.

21. K. Kiran, K. Suresh Kumar, B. Prasad, K. Suvardhan, L. Ramesh Babu, and K. Janardhanam, J. Hazard. Mater. 150 (2008) 582586.

22. J. L. Manzoori, H. Abdolmohammad-Zadeh, and M. Amjadi, J. Hazard. Mater. 144 (2007) 458-463.

23. M. A. Mesquita da Silva, V. L. A. Frescura, and A. J. Curtius, Spectrochim. Acta, Part B 56 (2001) 1941-1949.

24. L. Tavakoli,Y. Yamini, H. Ebrahimzadeh, A. Nezhadali, and S. Shariati, F., J. Hazard. Mater. 152 (2008) 737-743.

25. N. Shokoufi and F. Shemirani, Talanta 73 (2007) 662-67.

26. A. Safavi, H. Abdollahi, M. R. Hormozi Nezhad, and R. Kamali, Spectrochim. Acta, Part A 60 (2004) 2897-2901.

27. A. M. Haji Shabani, S. Dadfarnia, A. A. Jafari, and Z. Shahbasi, Can. J. Anal. Sci. Spectros. 51 (2006) 194-199.

28. H. Ashkenani, S. Dadfarnia, A. M. Haji Shabani, A. A. Jaffari, and A. Behjat, J. Hazard. Mater. 161 (2009) 276-280.

29. Z. Shabazi, S. Dadfarnia, A. M. Haji Shabani, and A. A. Jafari, J. Anal. Chem. 63 (2008) 446-450.

30. S. Dadfarnia, A. M. Haji Shabani, E. Kamranzadeh, Talanta 79 (2009) 1061-1065.

31. L. J. Theriot, C. C. Lee, and A. Syamal, Inorg. Chem. 10 (1971) 1669-1673.

32. Y. Muto, Bull. Chem. Soc. Jpn. 33 (1960) 1242-1247.

33. R. P. Frankewich and W. L. Hinze, Anal. Chem. 66 (1994) 944 954.

34. M. E. F. Laespada, J. L. P. Pavón, and B. M. Cardero, Analyst 118 (1993) 209-212.

35. D. Citak and M. Tuzen, Food Chem. Toxicol. 48 (2010) 1399 1404.

36. J. L. Manzoori and A. Bavili-Tabrizi, Microchem. J. 72 (2002) $1-7$.

37. F. Shemirani, S. D. Abkenar, and A. Khatouni, Bull. Korean Chem. Soc. 25 (2004) 1133-1136.

38. F. Shemirani, M. R. Jamali, R. R. Kozani, and M. SalavatiNiasari, Sep. Sci. Technol. 41 (2006) 3065-3077.

39. V. A. Lemos, J. S. Santos, and P. X. Baliza, J. Braz. Chem. Soc. 17 (2006) 30-35.

40. V. A. Lemos, M. S. Santos, M. J. S. dos Santos, D. R. Vieira, and C. G. Novaes, Microchim. Acta 157 (2007) 215-222.

41. P. Biparva and M. R. Hadjmohammadi, Acta Chim. Slov. 54 (2007) 805-810.

42. V. A. Lemos, M. S. Santos, G. T. David, M. V. Maciel, and M. A. Bezerra, J. Hazard. Mater. 159 (2008) 245-251.

43. N. Şatiroğlu and Ç. Arpa, Microchim. Acta 162 (2008) 107-112.

44. M. Ghaedi, A. Shokrollahi, K. Niknam, E. Niknam, and M. Soylak, Cent. Eur. J. Chem. 7 (2009) 148-154.

45. M. Ghaedi, A. Shokrollahi, K. Niknam, and M. Soylak, Sep. Sci. Technol. 44 (2009) 773-786. 